Please quote as: Kipp, P.; Bittner, E. A. C.; Bretschneider, U. \& Leimeister, J. M. (2014): User collaboration for idea elaboration. In: Mulitkonferenz Wirtschaftsinformatik (MKWI), Paderborn, Germany. 


\title{
User Collaboration for Idea Elaboration
}

\section{Philipp Kipp}

Universität Kassel, Fachgebiet Wirtschaftsinformatik, 34121 Kassel, E-Mail: philipp.kipp@unikassel.de

\section{Eva Alice Christiane Bittner}

Universität Kassel, Fachgebiet Wirtschaftsinformatik, 34121 Kassel, E-Mail: bittner@uni-kassel.de

\section{Dr. Ulrich Bretschneider}

Universität Kassel, Fachgebiet Wirtschaftsinformatik, 34121 Kassel, E-Mail: bretschneider@unikassel.de

\section{Prof. Dr. Jan Marco Leimeister}

Universität Kassel, Fachgebiet Wirtschaftsinformatik, 34121 Kassel, E-Mail: leimeister@uni-kassel.de

\begin{abstract}
Web-based innovation platforms (WBIP) are common tools for the integration of customers and other external stakeholders into the product and service innovation processes of companies. WBIP of many large companies are very successful in generating many ideas. This leads to WBIP operators drowning in lots of possibly creative and high potential ideas, which are difficult to screen. Therefore, this paper suggests a collaboration process allowing customers to participate collaboratively in the elaboration of self-selected ideas. The collaboration process was being developed following the collaboration process design approach and was designed to be adaptable into WBIP. The contribution of this paper is a novel approach to collaborative user integration into the idea elaboration process.
\end{abstract}

Keywords: WBIP, Open Innovation, Collaboration Engineering, CSCW

\section{Introduction}

In recent years, many companies have started integrating their customers into product and service development processes to gain better insight information of the consumers. This phenomenon is commonly described as Open Innovation, a term coined by Henry Chesbrough [5] for opening innovation processes of a company to external stakeholders. While Open Innovation covers the whole innovation process of a company, especially the integration of customers into the early stages of product or service innovation has caught a lot of attention in theory and practice [2], [7], [11], [15]. The trend to open up different aspects of the value chain combined with the rise of the Internet as a simple way to communicate with a broad auditorium allows new forms of customer integration. 
Without current technology, customer integration has only been possible by interviewing small samples of lead users [15] or conducting large standardized surveys. Web-based innovation platforms (WBIP) for implementing Virtual Idea Communities or online Idea Competitions now allow all customers to share their insights, opinions and ideas regarding a product with the manufacturer or other customers [9]. Popular WBIP such as Dell Ideastorm ${ }^{1}$, Innocentive ${ }^{2}$ or My Starbucks Idea ${ }^{3}$ and many other platforms were developed by companies trying to get their customers to generate many innovative ideas. Ideas generated on these WBIP can include new products or services, product or service improvements, marketing campaigns or distribution channels. WBIP summon customers who are mostly intrinsically motivated to contribute to the development of the products [8], [12], [14].

In order to enable the companies to identify high quality ideas worth beeing implemented, the approach suggested in this paper is a collaborative idea elaboration process. In this process, the community of WBIP members selects promising ideas and collaboratively elaborates these ideas by contributing their own point of view on the underlying problem description of the ideas and possible new approaches to implement these ideas. The result of the process is a richer, more elaborated description of the idea, which has been chosen to be promising by the community. The elaborated problem description is depicting the ideas' relevance to the community and is able to serve as a basis to decide, if the idea is worth pursuing and the elaborated solution description can give an improved starting point for internal feasibility analysis.

This paper details the development of a web-based collaborative idea elaboration process that can be adapted to different kinds of WBIP. It aims to develop a structured tool-supported process to enable collaborative elaboration of ideas by participants on a WBIP. The goal of the process is to enhance an initial idea into the description of a relevant problem and a feasible detailed description of a possible solution of this problem. In this paper, we show the development of the collaboration process design based on the Collaboration Process Design Approach and a pilot implementation of the process. The research questions answered in this paper are the following:

- How can a repeatable collaboration process improve the idea elaboration in WBIP?

- What is a possible technical implementation of the developed process?

- To which extend does the collaborative idea elaboration process increase idea quality?

The paper will be structured as follows: Section 2 describes the process of designing the collaborative idea elaboration process. It explains how the collaboration process design approach (CoPDA) [10] is used for the development of the process and how the consensual assessment technique [1] is used for the evaluation of the ideas resulting from the process. Chapter 3 displays the results of the proof of concept. Part 4 explains the limitations of this paper and section 5 summarizes the findings of this paper and points out the practical and theoretical contribution.

\section{Development based on the collaboration process design approach}

In this section, the process of how to design an innovative collaborative idea elaboration process will be shown. This paper adheres to design science research guidelines, which aim to develop solutions to organizational and business problems through designing and evaluating novel artefacts. To achieve this, design research focuses on the creation of innovative and purposeful artefacts for a specified

\footnotetext{
${ }^{1}$ http://www.ideastorm.com/

${ }^{2} \mathrm{http}: / /$ www.innocentive.com/

${ }^{3} \mathrm{http}: / /$ mystarbucksidea.force.com/
} 
problem domain. Such artefacts include new constructs or prototypes, and new methods for their development. In the case of this paper, the artefact to be designed is a collaborative idea evaluation process. Following the design science guidelines by Peffers et al.[13], we will first elaborate the specific requirements for the success of the process, before the steps of the process will be detailed. The complete process was evaluated in three proof of concept workshops with 6 participants each focusing on the elaboration of one idea per experiment. In order to develop the collaboration process, we choose collaboration engineering methodology, as it aims at "designing collaborative work practices for high-value recurring tasks, and deploying those designs for practitioners to execute for themselves without ongoing support from professional facilitators" [6]. Kolfschoten and de Vreede [10] provide a systematic five step approach for the design of the collaboration process. Figure 1 displays the collaboration process design approach, which we follow in our research. The first step encompasses the analysis of the involved task, group, and stakeholders. It results in a definition of the group goal and requirements for the collaboration process. In the second step, the group task is decomposed into a set of activities that should be executed to reach the group goal. The third step aims at selecting collaboration process design patterns (thinkLets) for each of the activities. ThinkLets are used to ensure systematic repeatability without ongoing professional facilitation. The thinkLet sequence is further developed into a detailed agenda in step four to specify the script, tool support, and scheduling of all activities. The final design of the process is validated against the desired results in order to identify the necessary adaption.

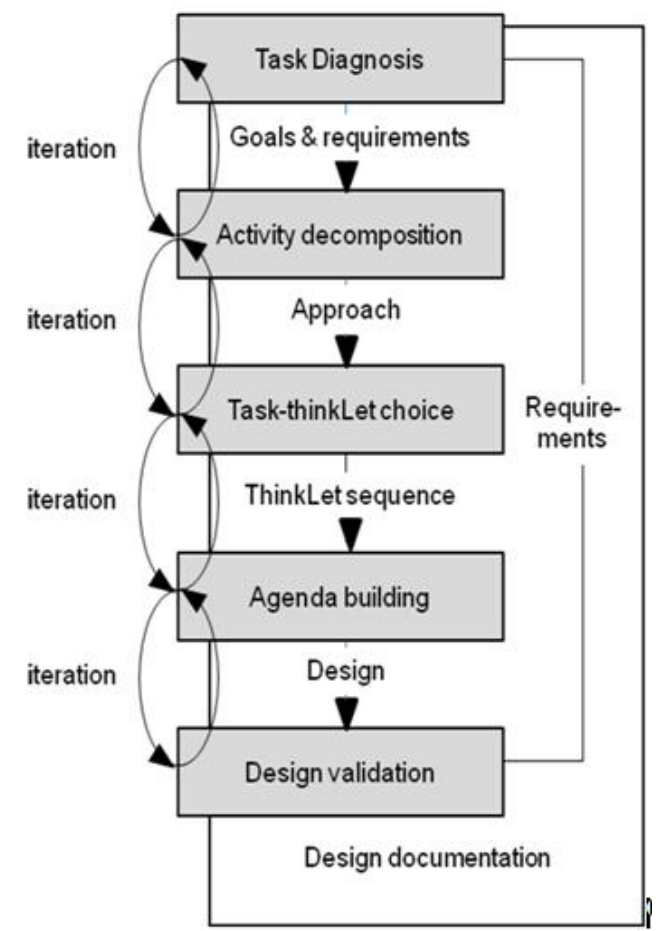

Fig. 1. The collaboration process design approach [10]

\subsection{Task diagnosis}

According to Kolfschoten and De Vreede the task diagnosis [10] is the necessary step to understand the environment as well as the goals of the collaboration process. The task diagnosis step takes a 
closer look at the collaboration tasks, the goals it should achieve as well as the deliverables of the process. The central goal of the collaborative idea elaboration process is the elaboration and improvement of an existing initial idea. This includes an assessment of the initial idea by the participants in the collaboration process as well as an augmentation of the idea by each user's comments and contributions. In order to be able to utilize every contribution of the participants, the completely elaborated idea is not the only deliverable developed in the process. Other deliverables are the comments contributed by each user to the definition of the idea's problem, the suggested solution as well as each user's evaluation of these comments. The combination of the comments and their evaluations result in a list of contributions that can be sorted and analyzed by the ratings of all participants.

The final elaborated idea should show a level of detail that allows organizations an easy assessment of the value and feasibility of the idea. Therefore, the problem description needs to point out the underlying problem from different perspectives and including a list of possible stakeholders. For the suggested solution, this means that it should include suggestions for possible idol projects (Who did something similar before?) or ideas of external service providers who could support the implementation of the idea. Ideally, the suggested solution already includes an estimate for the expected implementation cost or schedule. A jury of experts in the idea's domain evaluates the quality of the resulting idea. A suitable method for the evaluation of ideas or other creative artifacts is the consensual assessment technique [1]. This multidimensional evaluation technique will allow an expert jury the distinct evaluation of the novelty, feasibility, simplicity, elaboration, and expected popularity of the idea. The jury's evaluation is the benchmark for the quality of the resulting elaborated idea.

After the ideas have been generated and rated positively, they are introduced into an organization internal decision making and implementation process. The design and implementation of these processes is not within the scope of this thesis. Another important goal of the collaboration process can be referred as an experience goal. The toll-supported collaborative idea elaboration process should show the users the acknowledgement for their contribution to the elaboration of an idea rather than just recording and processing their input. This is due to the fact that the process will be repeated in many instances, which rely on the same user base - the users of the web-based ideation platform. By providing a positive reinforcement to participate in the collaboration process, users are more likely to come back and contribute their insights to the elaboration of the next idea.

\subsection{Activity decomposition}

This step of the collaboration process design approach divides the process into smaller steps with clearly defined goals and results. This step is necessary to enable the collaboration engineer to select the appropriate tools and thinkLets for each activity.

Figure 2 shows the sequence of necessary actions to achieve the collaboration goal of understandable and well elaborated ideas. The top of each block indicates the title of the activity. The figure also includes the respective layer of collaboration for each activity. The task presentation is supposed to inform the participants of the structure and the overall goal of the following collaboration process. This task results in the understanding and awareness of the participants regarding the following process steps. In the second task problem extraction, the participants have their first contact with the idea. The participants are supposed to read the initial idea and identify the parts that directly correspond to the underlying problem the idea is trying to solve. The goal of this activity is the categorization of the idea and the identification of the essential problem. The results are the parts of the initial idea's text corresponding to the basic issue. The next activity is problem elaboration. In this 
task, the collaborative goal is the generation of a problem description covering different aspects of the original problem. This activity creates a clear understanding of the problem that the group is going to solve during the collaboration process. The result is a textual description of different aspects of the problem.

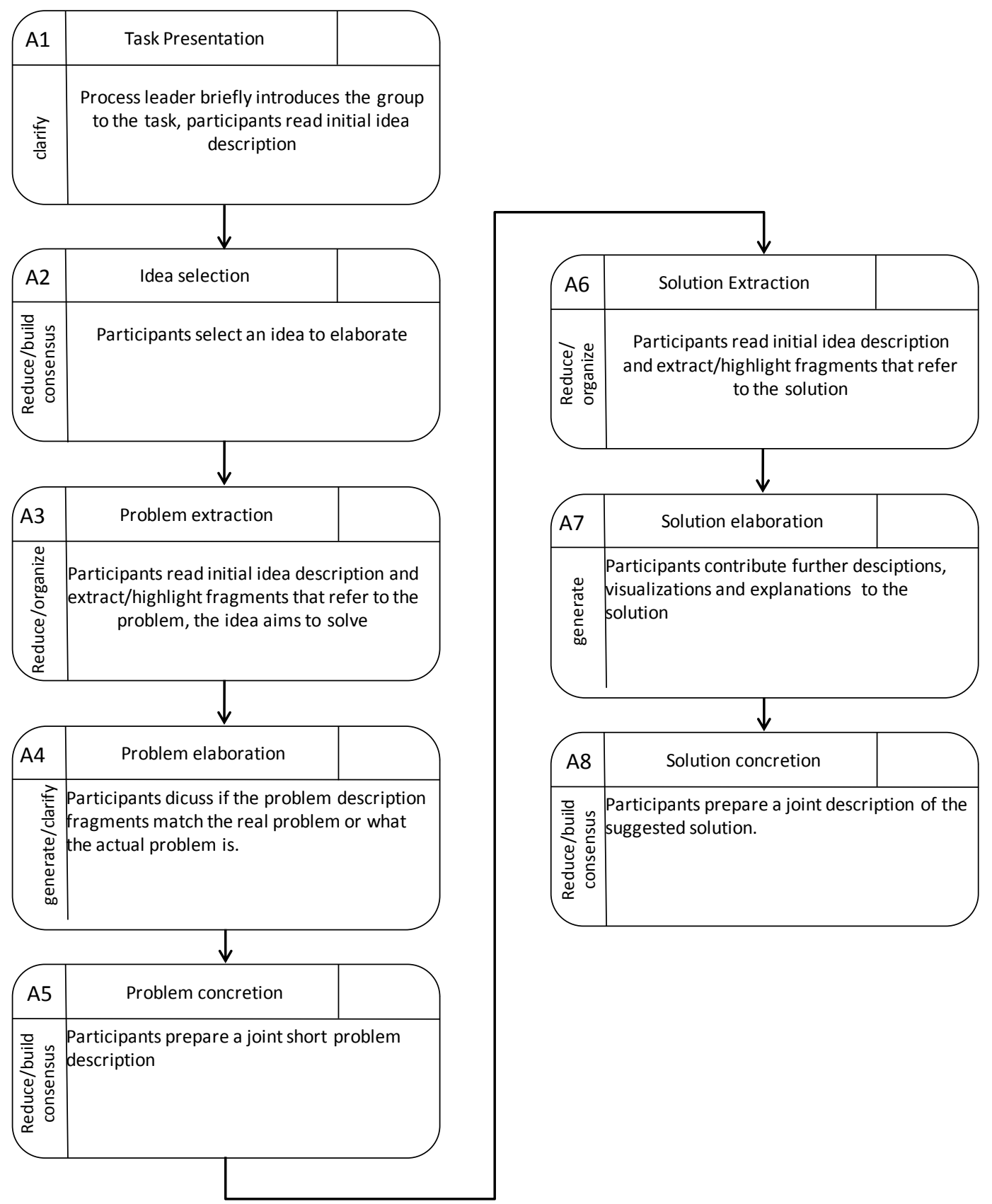

Fig. 2. The collaborative idea elaboration process

In the problem concretion activity, the participant will reduce the description of the problem to the most important aspects. This achieves two important goals: The participants are forced to build consensus regarding the important aspects of the problem, and the idea is reduced and rewritten in a readable form that helps to convince others of the relevance of the problem. The activities solution extraction, solution elaboration, and solution concretion are following the same structure as the three 
foregoing activities but they are elaborating on a solution of the previously identified and agreed upon solution.

\subsection{Task thinkLet choice}

Based on the activity decomposition, there is a thinkLet assigned to each activity. A thinkLet is a predefined pattern of collaboration designed to achieve a defined goal. The selected thinkLets can be found in Table 1. The thinkLet selection is based on "ThinkLets - Building Blocks for Concerted Collaboration" by Briggs and de Vreede [3].

Table 1. Collaborative actions and the corresponding layers of collaboration and thinkLets

\begin{tabular}{|l|l|l|l|}
\hline Action No. & Action Title & Layer(s) of collaboration & ThinkLet \\
\hline 1 & Task presentation & Clarify & - \\
\hline 2 & Idea selection & Reduce/Build consensus & MultiCriteria \\
\hline 3 & Problem extraction & Reduce/Organize & Popcornsort \\
\hline 4 & Problem elaboration & Generate/clarify & OnePage \\
\hline 5 & Problem concretion & Reduce/Build consensus & OnePage \\
\hline 6 & Solution extraction & Reduce/Organize & Popcornsort \\
\hline 7 & Solution elaboration & Generate & OnePage \\
\hline 8 & Solution concretion & Reduce/Build consensus & OnePage \\
\hline
\end{tabular}

Not every task could exactly be matched by the thinkLets defined by Briggs and de Vreede [3]. This made it necessary to make some changes to the original thinkLet definitions with respect to the environment of the collaboration process. A tasks is a presentation and no collaborative work that would be covered by a thinkLet. The first thinkLet used in the process was a MultiCriteria voting to support the participants in selecting the idea their group will elaborate. The criteria are defined as originality, feasibility, and relevance. The scale for each criterion is a five point Likert scale. The results for each criterion were added to identify the most popular idea for the group. The idea elaboration process consists of two phases with each three very similar actions. Both phases use the same thinkLets for their activities. The first step in each phase is the extraction of the solution/problem using a modified version of the Popcornsort thinkLet. The modification we made was that the participants should assign a part of the original idea of the problem/solution (depending on the action) or leave it in the primary way. There were no alternative buckets given to them. For the two actions problem elaboration and concretion, the same OnePage thinkLet page is used.

\subsection{Agenda building}

Based on the selected thinkLets, the detailed agenda for the evaluation was created. The agenda is supposed to give an exact structure to the process and provide guidance. In addition to the thinkLet choice, it defines the usage of the group support system as well as what is communicated to the 
participants. The group support system used for the implementation of this process is ThinkTank. The software offers support for all thinkLets defined in the previous section.

In order to motivate the participants to develop creative ideas and think in different ways, the agenda includes guiding questions for the problem and solution elaboration actions. The questions for the problem elaboration are designed to support participants' arguments for the relevance of the problem. The guiding questions for the solution elaboration try to support the participants to define a concrete use of the solution and possible external support for the implementation.

\subsection{Design validation}

In order to evaluate the collaboration process, we conducted a proof of concept implementing the process described previously. The goals were: Testing whether the collaborative elaboration increases idea quality, to measure participant satisfaction with the collaboration process, and to monitor participant behavior during the process evaluation workshops.

Since the ideas to be elaborated were about measures to improve teaching, learning or living at the university, students were selected to participate. In each of the three workshops, there were 5 voluntary student participants from different fields. Among the participants there were majors in economics, engineering, art and computer sciences Prior to the workshops, all participants were asked to point out an idea to improve the mentioned fields without giving them a clear indication what the target of the evaluation workshops would be. This procedure was supposed to create starting ideas for the collaboration process - structurally similar to ideas found on WBIP. Every participant got access to every idea the members brought to the workshop and could select one of the ideas for further elaboration. Further details of the process evaluations workshops is given in section 3 of this paper.

\subsection{Software implementation}

After this pretest of the process, the collaboration process was integrated into a WBIP. The implemented prototype is based on the CMS System Drupal 6 and was implemented as an independent module that can easily be integrated into any other Drupal based WBIP. This allows a broad evaluation of the tool in lab experiments and field test with different groups of participants. The results of these evaluations and experiments serve as a base for future revisions of the tool.

In order to represent the described process as a software artifact, we implemented a collection of features to fit the needs of the different process steps. The process steps for the identification and definition of the problem and the solution of the idea (A1 and A3) have been implemented as a brainstorming. Every user of the WBIP platform can participate in this activity without restrictions of time and place. In these brainstormings the participants are asked to contribute aspects of the problem they deem to be important. These can be short problem aspects from the original description of the initial idea or aspects the original idea did not include so far in the original problem/solution description but seems to be important to the brainstorm participant. Thus, the original idea description is augmented by the creativity, needs, and perception of the collaboration process participants. In order to obtain a sense of relevance for each of the brainstorming contributions, the participants can vote on each contribution. This gives the participants the opportunity to evaluate the collaboratively collected problem or solution aspects and to use this evaluation in the following process steps. Both process activities A2 and A4 follow the brainstorming activities and give the participants the chance to vote on all brainstorming contributions, but remove the functionality to contribute new problem or solution aspects. By adding these activities to the process, all contributions could be evaluated with enough time before the process proceeds to the final activities. The process steps of problem and solution 
concretion (A5 and A6) are realized based on the collaborative word processor Etherpad Lite ${ }^{4}$. This tool is embedded into the WBIP and allows the participants to write a conclusive text respectively for the problem and the solution description. Possible editing conflicts are avoided by enabling the participants to simultaneously write in the text fields. The writing progress is constantly tracked to make every stage of the text development transparent for the researchers.

Each of the process activities strongly relies on the outputs of the preceding process steps. To ensure this, it is always possible for each participant to see all results of the completed and ongoing process activities.

\section{Process evaluation workshops}

This paper develops a collaborative idea elaboration process. A good evaluation is crucial in order to validate the process and to guide future research. The evaluation of the process was carried out in three evaluation workshops with groups of German university students. Each group consisted of five students from different majors (economics, engineering, art and computer sciences) The collaborative idea elaboration process was set up in a local network on the group support system ThinkTank. In order to control any external influences, all participants were invited to the laboratory. This allowed the researchers to keep the communication of the participants closer to the environment than one would find on a WBIP. The group support system allows to follow the exact progress of the ideas made in the collaborative elaboration.

There are several different kinds of results from the proof of concept: The first is the observation of the researchers during the workshops. This is a very important source for future revisions of the collaboration process. The researchers observe at which process points the participants use verbal discussions or other means of communication a tool-based process implementation on a website should support. Additionally a survey based on Brigg's General Meeting Assessment Survey [4] is conducted among the participants to measure their satisfaction with the collaboration process. The most important results are the original as well as the collaboratively elaborated ideas. The quality of the original ideas are compared with the elaborated ones in an expert rating using Amabile's consensual assessment technique [1]. This gives insight into the extent to which the collaborative idea elaboration process improves idea quality.

\subsection{Observation results}

The participants followed the steps according to the collaboration process design. The steps problem extraction and problem concretion worked exactly according to the planned process. The participants copied the relevant parts of the original ideas and agreed on their improvements by using the adding and editing functionalities of the group support system. In the following steps of extracting and concreting the possible solutions, the participants very often used communication outside of the textbased group support system. Most of them used direct face-to-face discussions during the solution concretion phase. One group even used a whiteboard to visualize relationships among concepts and to develop a shared understanding of the problem solution. This shows us that just a text based collaboration is inconvenient for high creativity tasks. Future revisions of the process, as well as the tools used for the process implementation, need to support additional ways of communication, such as direct chat, separate discussions or graphic display of ideas, to support shared understanding among the participants.

\footnotetext{
${ }^{4} \mathrm{http} / / / \mathrm{www} . e t h e r p a d . o r g$
} 
The evolution of the ideas shows the contribution a collaborative effort can make. While the problems of the initial ideas were mostly adopted, new ideas for possible solutions were found in the process. While not all of the resulting ideas could be implemented easily, well elaborated ideas can help to "sell" the idea to people and make them aware of how they could profit from the implementation. This shows that the structured collaborative process not only enables the participants to combine their knowledge and ideas, but also create new value by building on the ideas of others. This is an important hint towards structured collaboration as a tool for successful elaboration of simple ideas.

\subsection{Participant satisfaction}

Additionally the participants were asked to fill out a general meeting assessment survey as suggested by Briggs et al. [4]. The survey tested the process and result satisfaction of the participants on a set of items measured on a 7 step Likert scale with seven being the highest value. The results of the onesample t-test against the neutral value 4 show a tendency towards a satisfactory perception of the collaboration process and result quality. At an average, process satisfaction was rated 4.52 (n.s.) and result satisfaction $4.63(\mathrm{p}<0.05)$. These values can be seen as a positive feedback and will serve as a benchmark for the evaluation of future revisions of the process.

\subsection{Idea quality evolution}

In the proof of concept, three ideas were collaboratively elaborated upon using the process described above. This section elaborates on the influence of collaborative elaboration on the quality of ideas. In order to do so, we used the consensual assessment technique by Amabile [1]. It uses multidimensional expert ratings to assess the quality of ideas. In this case, we surveyed a jury of five university employees with at least three years of job experience. This ensures that the jury members are capable of evaluating improvement ideas. The evaluation survey assessed five distinct items to evaluate different dimensions of idea quality. The items included in the survey were originality; feasibility; benevolence; simplicity, and completeness. Each item was operationalized by one claim. The jury members were asked to express their agreement on each claim on a 5-step Likert scale. They did not know which of the ideas were initial or elaborated and evaluated the ideas in random order.

The original claims were in German, given here with the corresponding translations:

- Item 1 (Originality):This idea is a new approach to assess its underlying problem for the university.

- Item 2 (Feasibility): This idea is easily feasible for the university.

- Item 3 (Benevolence): This idea has the potential for benevolence among the students of the university.

- Item 4 (Simplicity): This idea solves its underlying problem in a simple way.

- Item 5 (Completeness): This idea is complete and well elaborated upon.

Every item rating was valued with a score from 1 (lowest) to 5 (highest). The first result of the expert rating is that the overall rating of each idea improved in the course of the collaboration process. Table 2 shows the overall scores for the initial, as well as the elaborated, ideas. 
Table 2. Idea evaluation results

\begin{tabular}{|c|c|c|c|c|c|c|c|c|c|c|c|c|}
\hline \multirow[t]{2}{*}{ Idea } & \multicolumn{6}{|c|}{ Initial } & \multicolumn{6}{|c|}{ Elaborated } \\
\hline & 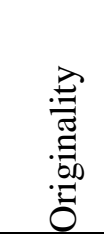 & 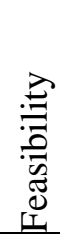 & $\begin{array}{l}0 \\
0 \\
0 \\
0 \\
0 \\
0 \\
0 \\
0 \\
0\end{array}$ & 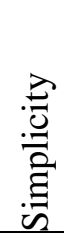 & 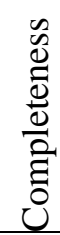 & $\stackrel{\pi}{0}$ & 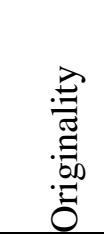 & 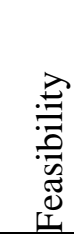 & 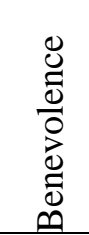 & 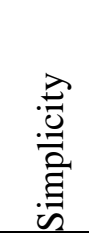 & 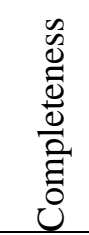 & \\
\hline 1 & 13 & 15 & 19 & 14 & 8 & 69 & $\begin{array}{c}15 \\
(+2)\end{array}$ & $\begin{array}{r}12 \\
(-3)\end{array}$ & $\begin{array}{c}21 \\
(+2)\end{array}$ & $\begin{array}{c}16 \\
(+2)\end{array}$ & $\begin{array}{c}13 \\
(+5)\end{array}$ & $\begin{array}{r}77 \\
(+8\end{array}$ \\
\hline 2 & 14 & 14 & 25 & 22 & 13 & 88 & $\begin{array}{c}18 \\
(+4)\end{array}$ & $\begin{array}{r}14 \\
(+0)\end{array}$ & $\begin{array}{c}24 \\
(-1)\end{array}$ & $\begin{array}{c}21 \\
(-1)\end{array}$ & $\begin{array}{c}19 \\
(+6)\end{array}$ & $\begin{array}{r}96 \\
(+8\end{array}$ \\
\hline 3 & 13 & 11 & 13 & 15 & 9 & 64 & $\begin{array}{c}16 \\
(+3)\end{array}$ & $\begin{array}{c}9 \\
(-2)\end{array}$ & $\begin{array}{c}17 \\
(+4)\end{array}$ & $\begin{array}{c}11 \\
(-4)\end{array}$ & $\begin{array}{c}11 \\
(+2)\end{array}$ & $\begin{array}{r}64 \\
(+3)\end{array}$ \\
\hline
\end{tabular}

Another important finding from the expert rating was that the improvements rates were not equally distributed among the items. The advancements for completeness and originality are very high; the improvements on feasibility and simplicity are instead negative, i.e., the elaborated ideas are rated worse for both items than the initial ideas.

The successful improvements of the items' originality and completeness coincide with the goals of the collaborative approach: To create a better elaborated version of the ideas using the creativity and originality of multiple participants.

The decline of the ratings for feasibility and simplicity can be explained by the higher complexity of the elaborated ideas. As multiple people collaborate and contribute their insights to the idea, more aspects are included into the solution. Therefore, the idea becomes more complex (negative simplicity) and more difficult to implement (negative feasibility).

\section{Limitations}

This section summarizes the threats to the validity of the work.

The internal validity of the evaluation could be threatened by the fact that we analyzed the resulting ideas but not the communication of the participants. The participants operated the process in the presence of the observer though without recording of the oral communication. The participants were encouraged to write down their questions and issues through the use of the group support system. Although we did not prevent oral communication in the evaluation, this is a limitation of this study.

Regarding external validity, the major concern is the generalizability of the results. Indeed the idea elaboration process was operationalized only three times with university students. We tried to limit this effect by selecting a topic in which students can be considered as experts and therefore suitable for the collaborative work. Due to the diversity of ideas and idea communities, we cannot claim that the 
results are representative for all idea communities. Further, the involved participants could have had an effect on the idea elaboration. This study is a first step to analyze the collaborative idea elaboration process. To strengthen the results, other ideas with other participants should be analyzed.

\section{Discussion and conclusion}

The collaboration process developed in this paper is an important step for successful collaborative idea elaboration on WBIP. The process was developed and evaluated following well established methodology of the field of Collaboration Engineering, especially the collaboration design approach by Kolfschoten and de Vreede, which was transformed to the presented needs. The article shows first results with a prototypal evaluation with students.

Collaboration Engineering and the collaboration process design approach provided the methodology for the development of collaborative processes. We used this body of knowledge to develop and pilot our collaborative idea elaboration process. The process is based on the separate identification and elaboration of the idea's underlying problem and its suggested solution by a group of idea stakeholders with knowledge in the idea's basic topic.

The evaluation by a jury of experts suggests that the overall quality of the idea improves during the collaboration process. The analysis shows an increase in quality, especially for the items elaboration and originality.

The contribution of this paper can be divided into theoretical and practical aspects. The theoretical aspect is the combination of different approaches from Information Systems, Collaboration Engineering and Innovation Management. Combining these three fields enables an increase in idea quality and therefore strengthens the Open Innovation approach. On the other hand, the practical perspective describes a step towards the implementation of collaboration tools on WBIP, so that platform providers could foster collaboration as well as an increase of idea quality on their platforms.

In summary, you can say that the results are based only on a small sample of ideas and few expert ratings, but they do indicate an improvement in the overall idea quality and especially in the elaboration and originality items. This shows that the collaborative idea elaboration process is a promising approach to improve idea quality. Besides, the results also demonstrate that the ideas generated in our collaboration process tend to become much more complex than the initial ideas. In future revisions of the process, one focus point will be to reduce complexity in the elaborated versions of the ideas.

This paper lays the foundation for our future research in user collaboration for WBIP. Future work will focus on improving the process and implementing it on an innovation community site at our university. Additionally, there will be user workshops focusing on the effectiveness of the tool implementation and on ways to motivate the users for the collaboration process. 


\section{References}

[1] Amabile, T.M. (1982): Social psychology of creativity: A consensual assessment technique. Journal of Personality and Social Psychology - PSP 43, 997-1013

[2] Blohm, I., Bretschneider, U., Leimeister, J.M., Krcmar, H. (2011): Does collaboration among participants lead to better ideas in IT-based idea competitions - An empirical investigation. International Journal of Networking and Virtual Organizations

[3] Briggs, R.O., de Vreede, G.-J. (2009): ThinkLets - Building Blocks for Concerted Collaboration, Omaha

[4] Briggs, R.O., de Vreede, G.-J., Reinig, B.A. (Year): A Theory and Measurement of Meeting Satisfaction. In: Conference A Theory and Measurement of Meeting Satisfaction. IEEE Computer Society Press,

[5] Chesbrough, H.W. (2003): The Era of Open Innovation. MIT Sloan Management Review 44, 3441

[6] De Vreede, G.-J., Briggs, R.O. (2005): Collaboration Engineering: Designing Repeatable Processes for High-Value Collaborative Tasks. 38th Hawaii International Conference on System Sciences,

[7] Di Gangi, P.M., Wasko, M. (2009): Steal my idea! Organizational adoption of user innovations from a user innovation community: A case study of Dell IdeaStorm. Decision Support Systems 48, 303-312

[8] Janzik, L., Herstatt, C. (2008): Innovation Communities: Motivation and Incentives for Community Members to contribute. IEEE International Conference on Management of Innovation and Technology (ICMIT), Bangkok

[9] Kipp, P., Wieck, E., Bretschneider, U., Leimeister, J.M. (2013): 12 Years of GENEX Framework: What did Practice Learn from Science in Terms of Web-Based Ideation? 11. Internationale Tagung Wirtschaftsinformatik, Leipzig

[10] Kolfschoten, G., De Vreede, G.-J. (2009): A Design Approach for Collaboration Processes: A Multi-Method Design Science Study in Collaboration Engineering. Journal of Management Information Systems 26, 225 - 256

[11] Leimeister, J.M., Huber, M., Bretschneider, U., Krcmar, H. (2009): Leveraging Crowdsourcing: Activation-Supporting Components for IT-Based Ideas Competition. Journal of Management Information Systems 26, 197-224

[12] Moore, T.D., Serva, M.A. (Year): Understanding Member Motivation for Contributing to Different Types of Virtual Communities: A Proposed Framework. In: Conference Understanding Member Motivation for Contributing to Different Types of Virtual Communities: A Proposed Framework.

[13] Peffers, K., Tuunanen, T., Rothenberger, M.A., Chatterjee, S. (2007): A Design Science Research methodology for Information Systems Research. Journal of Management Information Systems 24, 45 77

[14] Reichwald, R., Piller, F. (2009): Interaktive Wertschöpfung - Open Innovation, Individualisierung und neue Formen der Arbeitsteilung. Gabler, Wiesbaden

[15] von Hippel, E. (2005): Democratizing Innovation. The MIT Press, Cambridge, MA 